\title{
Modelling of sintering during rotational moulding of the thermoplastic polymers
}

\author{
A. Hamidi ${ }^{*}$, S. Farzaneh ${ }^{1}$, F. Nony ${ }^{2}$,Z. Ortega ${ }^{4}$, S. Khelladi ${ }^{3}$, M. Monzon ${ }^{4}$, F. Bakir ${ }^{3}$,A.
} Tcharkhtchi ${ }^{1}$

\author{
${ }^{1}$ PIMM, Arts et Métier ParisTech, 151 Bd de l'Hôpital 75013 Paris, France. \\ ${ }^{2}$ CEA le Ripault, 37260 Monts, France. \\ ${ }^{3}$ DynFluidLaboratory, Arts et Métier ParisTech, 151 Bd de l'Hôpital 75013 Paris, France. \\ ${ }^{4}$ Universidad de Las Palmas de Gran Canaria, Edificio de fabricación integrada.35017. Las \\ Palmas Gran Canaria, Spain.
}

\begin{abstract}
.
This paper concerns the study of sintering phenomenon during rotational molding of polypropylene(PP), Polyvinylidenefluoride (PVDF) and Polymethyl methacrylate (PMMA).

First, the coalescence (first step of sintering) of two grains has been followed. Bellehumeur's model has been tested as a model to explain this phenomenon.

In order to study the effect of neighboring grains on coalescence of two grains, a third grain has been put in contact with these two grains. For modeling the phenomenon in this case, Bellehumeur's model has been modified by a geometric parameter called Farz Factor (FF), being this model validated by experimental test.

Concerning densification, two different stages have been observed. In the first stage, before welding of the grains and formation of interphases between them, the grains are not stuck yet. The air trapped between the grains escapes through free ways between grains. This first step of densification is directly related to the coalescence where the density of the polymer varies very quickly. A new tridimensional model, based on a Body Centered Tetragonal(BCT) configuration, has been proposed to explain the densification during this first stage. In the second stage, the migration of air is controlled by diffusion.
\end{abstract}

Key words:Sintering, coalescence, densification, modeling. 


\section{Introduction}

Rotational moulding is a technique to manufacture the hollow industrial parts [1-3]. It is generally an empirical method to make products with different geometries. Due to the nature of the process, certain defects may be introduced in the structure of part. One of these defects is the formation of bubbles during rotational moulding. Indeed, in this process, the polymer is used in powder shape and during melting the air between the grains can be trapped and creates the bubbles in molten polymer. If these bubbles remain in the structure at the end of process, they can decrease the mechanical properties of the parts. The question is how the bubbles can be removed during rotational moulding?

During rotational moulding, the physical state of polymer changes from solid to liquid and from liquid to solid. These changes of physical state can be presented by time-internal air temperature diagram (Figure 1). Time-internal air temperature diagram gives valuable information about the polymer during rotational moulding. On this diagram, point A corresponds to the melting of the first grains in contact with the internal surface of the mould. Segment AB corresponds to the coalescence of the grains and formation of molten polymer layers. After the formation of the first layers, the part will be consolidated by the formation of the successive molten layers under the effect of melting and densification.

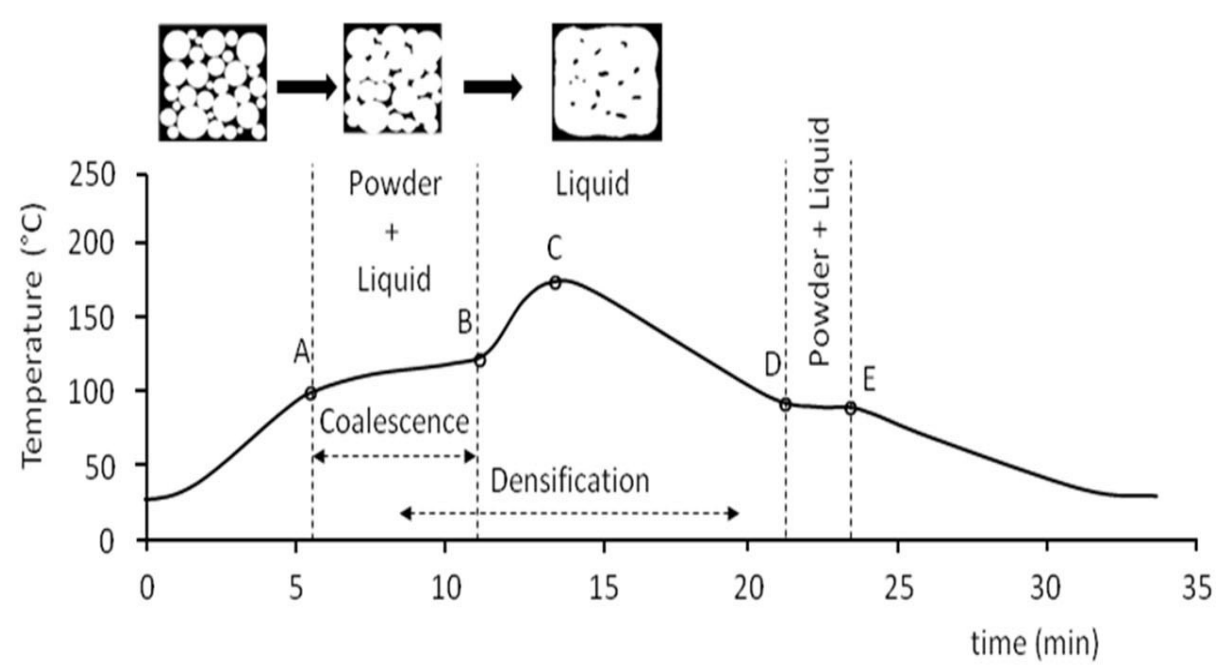

Figure 1.Time-internal air temperature diagram during rotational moulding 
At point $\mathrm{B}$, all of the grains are melted. Densification is the predominant phenomenon during the period related to the segment $\mathrm{BC}$. The air between the grains, trapped in the molten polymer, will form the bubbles. They will be pushed out of the powder and molten layers to be eliminated when polymer is in molten state (period CD before the beginning of crystallization, point D). The release of bubbles depends on different parameters specially temperature and its rate. This phenomenon is controlled by coalescence of the grains and by densification phenomenon.

In literature, there are many papers explaining the sintering phenomenon [4-8]. In general, the sintering of polymer powder may be distinguished by two successive phenomena, coalescence and densification.

i) Coalescence [9-10] is the formation of an interphase between two grains in contact, at temperature higher than their melting point and inter-diffusion of the molecular chains of two grains to form only one particle (Figure 2). The coalescence of polymer grains depends on different parameters especially the surface tension, viscosity and the relaxation time.
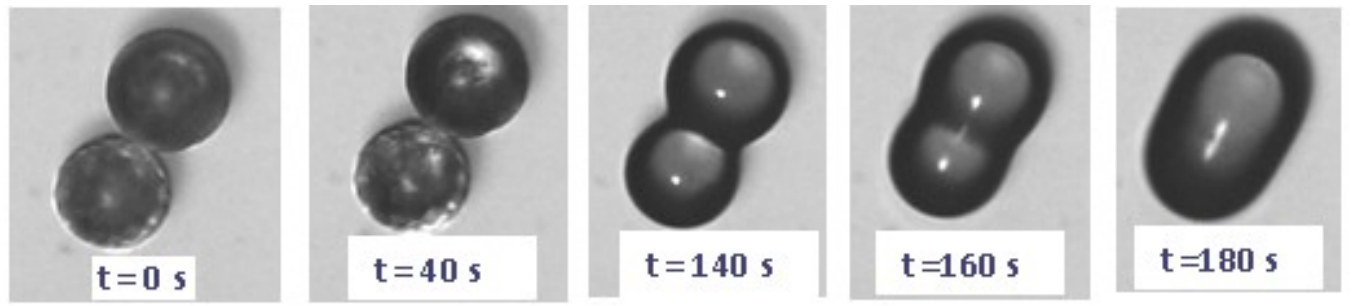

Figure 2.Different steps of coalescence of two polymer PVDF particles $(60 \mu \mathrm{m})$.

The study of coalescence is not limited to the polymers; this phenomenon has been studied first in ceramics and metals. The first ideal model for coalescence was proposed by Frenkel in 1945[11]. According to Frenkel, the viscosity, the surface tension and the size of the grains are the influent parameters on coalescence of two grains. However, the model proposed by Frenkel cannot consider all aspects related to the polymers in particular the visco-elastic behaviour. Later, other models have been proposed for example, Lontz introduced the relaxation time of polymer into the model of Frenkel[12].

Recently Bellehumeur [7,13] has proposed a new model (equation (1)), which can explain the coalescence of two grains in three dimensions. This model has been applied by different research studies on different polymers $[14,15]$. 


$$
8\left(r \tau A_{1} \phi\right)^{2}+\left(2 r \tau A_{1}+\frac{\eta r_{0}}{\gamma} \frac{A_{1}^{2}}{A_{2}}\right) \cdot \phi-1=0
$$

With :

$$
A_{1}=\frac{\sin \phi}{(1+\cos \phi)(2-\cos \phi)}
$$

and

$$
A_{2}=\frac{2^{-\frac{5}{3}} \cos \phi \cdot \sin \phi}{(1+\cos \phi)^{\frac{4}{3}}(2-\cos \phi)^{\frac{5}{3}}}
$$

Where: $r$ : radius of grains, $r_{0}$ : initial radius, $\gamma$ : surface tension, $\tau$ :relaxation time, $\eta$ :viscosity, $\sin \phi=\mathrm{x} / \mathrm{r}$ : coalescence rate and $\mathrm{x}$ is the half the neck between two grains during the coalescence

It was shown that the evolution of the interface of the grains (neck of the coalescence) is directly related to the volume fraction of air in the system. In bellehumeur's model, the neck is followed during the time for two different arrangements of the grains; Simple Cubic (SC) and Face Centred Cubic (FCC) arrangement (Figure 3).

(a)

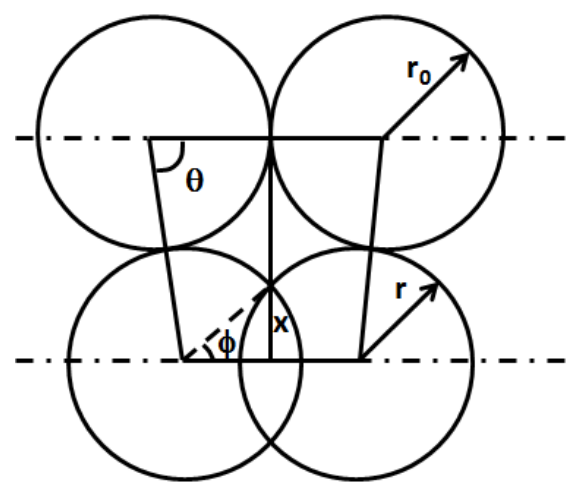

(b)

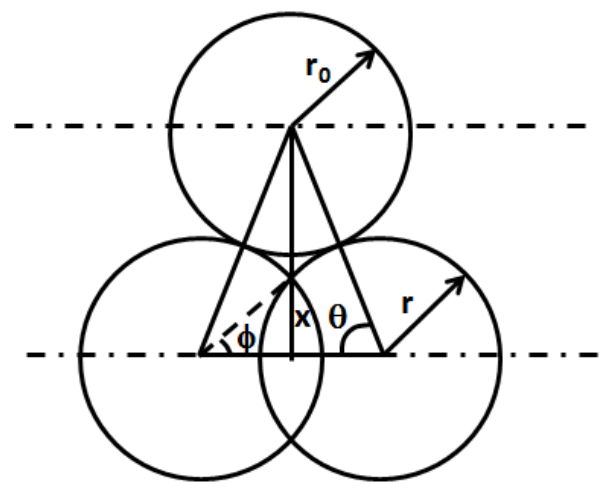

Figure 3. Two different arrangements of grains in Bellehumeur model (a) Simple Cubic (SC); (b) Face Centred Cubic (FCC) 
In both cases, the surface of contact between grains was calculated, by equations (2) and (3).

$A_{S C}=\left(r_{0}+r \cos \phi\right)\left(r_{0}+r\right) \sin \theta-r_{0}^{2}-r^{2}(\pi-\theta-\phi)-r^{2} \cos \phi \sin \phi$

$A_{F C C}=r \cos \phi \sin \theta\left(r_{0}+r\right)-\frac{1}{2} r_{0}^{2}(\pi-2 \theta)-a^{2}(\theta-\phi)-a^{2} \cos \phi \sin \phi$

ii) During rotational moulding, the coalescence of the grains leads the thickening of powder, called also densification. Densification is the phenomenon of transformation of powder to the homogenious molten layers. The density of the powder increases during densification. Different studies are carried out to show the relationship between this phenomenon and the phenomenon of coalescence [16-18].

In rotational moulding process, powder melts freely, and there is not any external force except gravity and surface tension to allow the release of air between the grains via densification phenomenon. The air between the powder particles exits in two steps during densification of grains:

- When the grains adhere to each other during sintering, the free spaces between the grains are reduced, and in consequence the air between the grains is released by the free spaces between them. This step of densification is controlled by coalescence phenomenon.

- Once these free spaces are closed because of the welding of the grains, the remaining air is trapped in the polymer melt and forms the air bublles. In this step of densification, the phenomenon of coalescence no longer exists, because all the grains are already welded to each other. In this case, densification occurs by gas diffussion into polymer.

Coalescence and densification are the main physical phenomena responsible of the formation of the part during rotation molding. In order to control the properties of the part, it is necessary to simulate the process. This simulation is based on the models explaining the sintering phenomenon. 
In this study the bellehumeur's equation has been used for modeling first the coalescence of two grains. Then it will be used for the first step of densification when air will be released only through the free spaces between the grains and not by diffusion. However, as this model does not take into cosideration, the effect of the other grains on the coalescence of two grains, it is necessary to modify it by a correction parameter.

\section{Materials and Methods}

\subsection{Materials}

The polymers used for this study were:

i) Polyvinylidene fluoride(PVDF), a semi-crystalline thermoplastic polymer supplied, in the form of powder, by SOLVAY Company.

ii) Polypropylene (PP) which is also a semi-crystalline thermoplastic polymer, supplied by ICO POLYMERS Company.

iii) Polymethyl methacrylate (PMMA)is an amorphous polymer which is supplied by PERSPEX Company.

\subsection{Characterization methods}

Different experimental methods were used to characterize these polymers.

- DSC measurements were carried out with the DSC Q10 V9.0 Build275 (TA Instruments). The samples of a mass between 10-20 mg were placed in hermetic aluminum capsules. The sample was heated first up to $200^{\circ} \mathrm{C}$ with a temperature rate of $5^{\circ} \mathrm{C} / \mathrm{min}$, in order to eliminate the effect of thermal history of the material. It was cooled down to $-60^{\circ} \mathrm{C}$ in order to be reheated up to $200^{\circ} \mathrm{C}$ with the same temperature rate.

- The surface tension of the polymers has been measured by DIGIDROP GBX machine with the adjustable heat sources and the probes for temperature control.

- Rheological properties were measured using an Ares Rheometer from TA Instruments equipped with $25 \mathrm{~mm}$ diameter parallel plates. Measurements are taken each 8 seconds and the gap between parallel plates is between 0.5 and $1 \mathrm{~mm}$ wide. Isothermal tests have been performed at $210^{\circ} \mathrm{C}$ and the viscosity has been measured taking the value of Newtonian level. Certain characteristics of these polymers are shown in table 1. 
Table 1.Characteristics of polymers under study

\begin{tabular}{|l|l|c|l|c|c|c|}
\hline Polymers & $\begin{array}{l}\text { Particle } \\
\text { shape }\end{array}$ & $\begin{array}{l}\text { Glass transition } \\
\text { temperature } \\
(\mathrm{Tg}),{ }^{\circ} \mathrm{C}\end{array}$ & $\begin{array}{l}\text { Particle } \\
\text { size } \\
(\mu \mathrm{m})\end{array}$ & $\begin{array}{l}\text { Melting point } \\
(\mathrm{Tm}),{ }^{\circ} \mathrm{C}\end{array}$ & $\begin{array}{l}\text { Surface } \\
\text { tension } \\
\mathrm{mN} / \mathrm{m}\end{array}$ & $\begin{array}{l}\text { Viscosity } \\
\text { at } 210^{\circ} \mathrm{C}, \\
\text { Pa.s }\end{array}$ \\
\hline PP & Spherical & -5 to 5 & $100-700$ & 167 & 29 & 1300 \\
\hline PVDF & Spherical & -35 & $20-100$ & 175 & 16 & 2380 \\
\hline PMMA & Irregular & 109 & $200-800$ & - & 25 & 2850 \\
\hline
\end{tabular}

\subsection{Microscopic analysis of coalescence}

The study of coalescence was carried out by a polarized light microscope (BH-2 from OLYMPUS) coupled with a temperature programmable heater (Mettler FP82). The tests have been performed according to the following protocol:

- Spread the powder of the polymer on the small glass blade or aluminium foil sheet

- Insert the blade under the microscope

- Choose the grains with desired sizes and shapes

- Remove the remainder of the powder

- Put in contact the selected grains

- Adjust the program of heating and set the image acquisition conditions

- Insert the blade in the heater chamber and put it under the microscope

- Start the test and take the pictures

The heating of the grains was performed in two stages. During the first stage, the grains were heated up to $5^{\circ} \mathrm{C}$ below their melting point at a heating rate of $10^{\circ} \mathrm{C} / \mathrm{min}$. In order to obtain an isothermal condition and to avoid temperature gradient in the grains, in the second stage, heating was performed at a slower rate of $1^{\circ} \mathrm{C} / \mathrm{min}$. Once reaching sintering temperature, isotherm condition was maintained by a central processor. The neck formed between the particles was measured at different time intervals using Ellix image analysis software. 
Coalescence rate is calculated as the ratio of the half of neck size and the grain radius at defined time intervals. The coalescence of two grains is considered to be complete when this ratio is equal to 1 .

To validate the experimental procedure, the same experiment was repeated by heating the grains separately up to their sintering temperature. At this temperature the grains are already melted. These melted grains were kept at sintering temperature for $10 \mathrm{sec}$ to obtain uniform temperature in the grains. The grains were then brought in contact and their sintering rate was measured. This sintering rate was compared with the one obtained from the previous experimental procedure.

\section{Results and discussion}

\subsection{Coalescence}

\subsubsection{Effect of Temperature}

To study the effect of temperature on coalescence rate, two experiments were performed on each polymer at two different temperatures. Figure 4 shows the results of these experiments on PP, PVDF and PMMA particles. It can be seen that the rate of coalescence increases by increasing of temperature.

This effect can be explained in term of the influence of temperature on viscosity, relaxation time and surface tension.
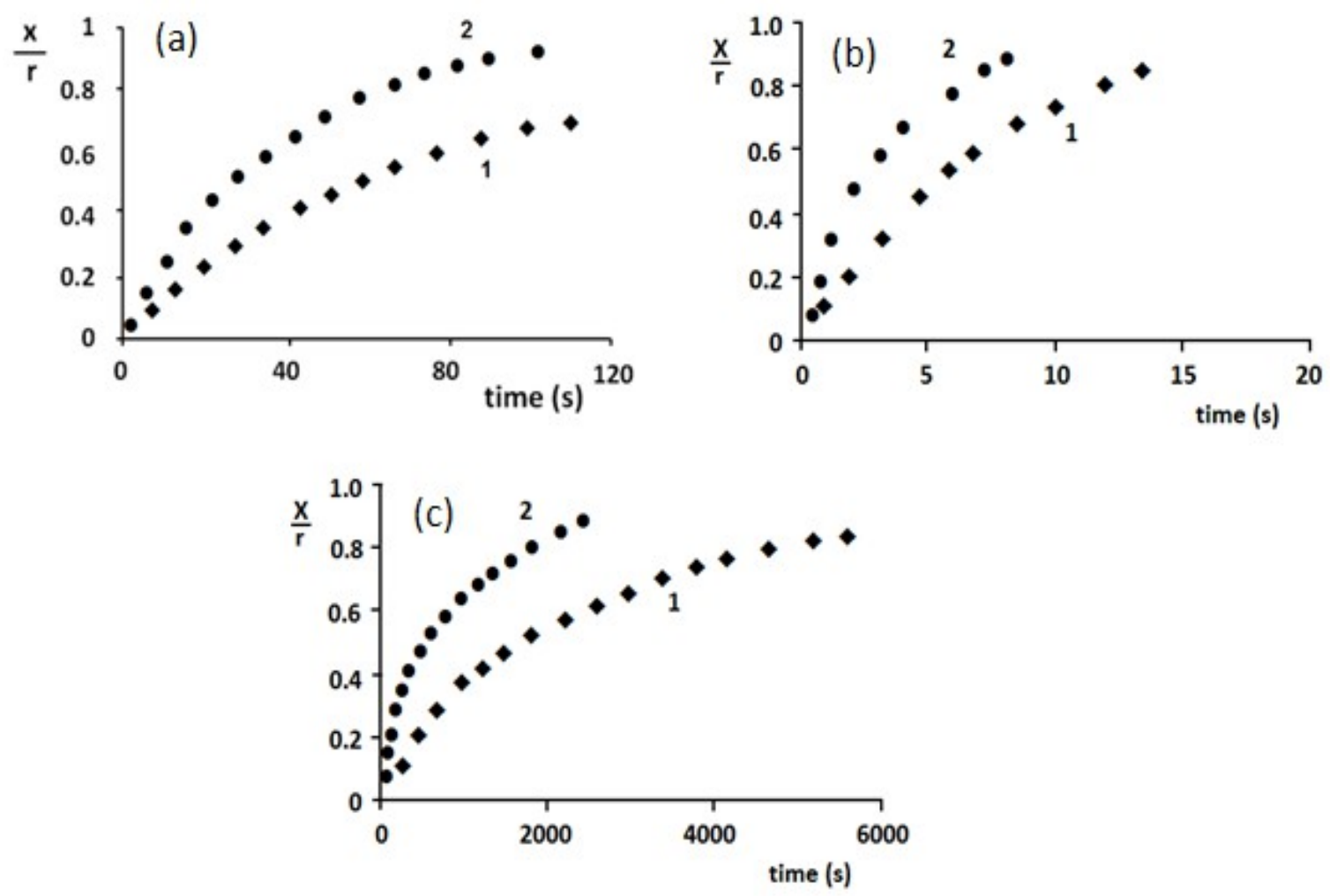
Figure 4.Influence of temperature on coalescence rate of:

a) $\mathrm{PP}$ particles $(600 \mu \mathrm{m}) .190^{\circ} \mathrm{C}(1), 210^{\circ} \mathrm{C}(2)$

b) PVDF particles $(100 \mu \mathrm{m}) .190^{\circ} \mathrm{C}(1), 240^{\circ} \mathrm{C}(2)$

c) PMMA particles $(260 \mu \mathrm{m}) .190^{\circ} \mathrm{C}(1), 220^{\circ} \mathrm{C}(2)$

\section{-Temperature dependence of viscosity}

By increasing of temperature the viscosity of the polymer decreases and the grains in their surfaces become more fluid. In this case, the inter-diffusion of the molecular chains in two grains is easier during coalescence.

The temperature dependence of viscosity of polymers is studied by the rheometer. The viscosity has been measured at different temperatures. The linear variation of $\ln \eta$ versus $1 / T$ (Figure 5) shows that the temperature dependence of viscosity of PP, PMMA and PVDF has Arrhenius behavior with activation energy respectively of 109, 57 and 31 KJ.mol ${ }^{-1}$.

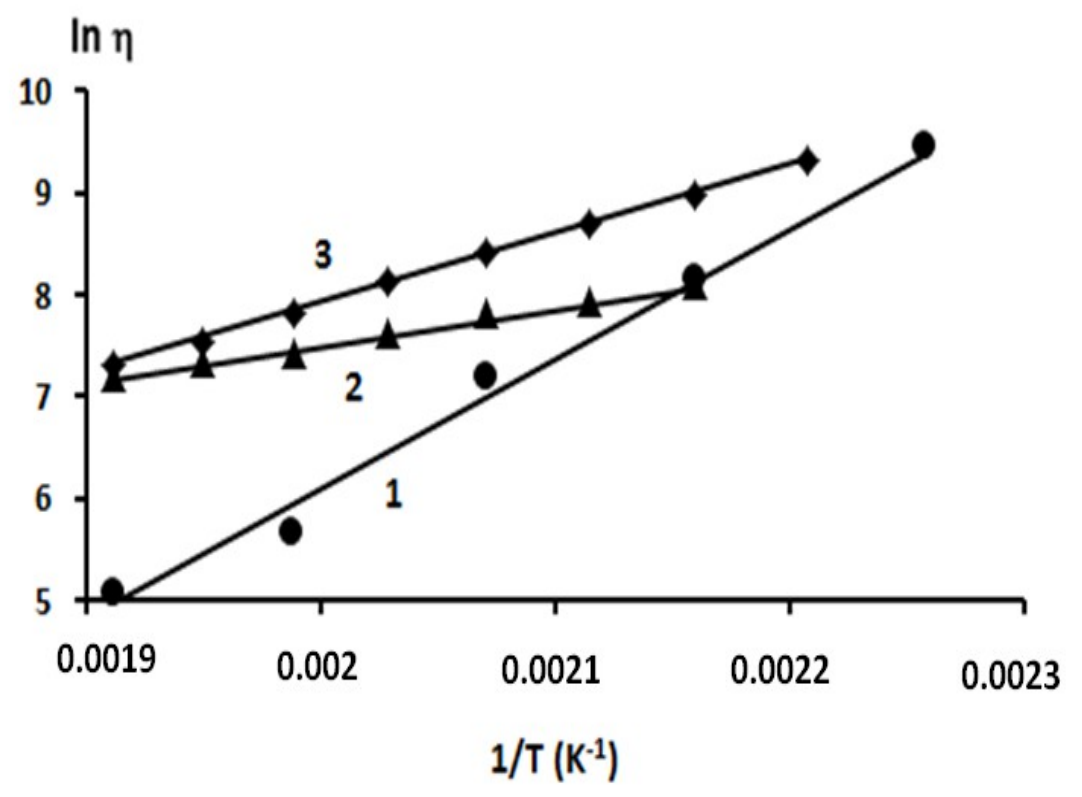

Figure 5.Temperature dependence of viscosity of PP (1), PVDF (2) and PMMA (3).

\section{-Influence of temperature on relaxation time}

First, by comparing the theoretical curve with the experimental results, it was verified that the viscosity variation of all three polymers at molten state versus angular frequency $(\omega)$, in 
isothermal condition, follows the Zener model (Figure 6a). Then, the relaxation time has been determined by COLE-COLE diagram (Figure 6b) as follows:

Zener model in dynamic loading is presented by the following equation:

$$
\eta^{*}(\omega)=\eta_{s}+\frac{\eta_{0}-\eta_{s}}{1+(i \omega \tau)^{1-\alpha}}=\eta^{\prime}(\omega)+i \eta^{\prime \prime}(\omega)
$$

with

$$
\eta^{\prime}(\omega)=\eta_{s}+\frac{\eta_{0}-\eta_{s}}{2}\left(1-\frac{\sinh [(1-\alpha) \ln (\omega \tau)]}{\sinh [(1-\alpha) \ln (\omega \tau)]+\cos \left[\frac{(1-\alpha) \pi}{2}\right]}\right.
$$

and

$$
\eta^{\prime \prime}(\omega)=\frac{\eta_{0}-\eta_{s}}{2}\left(1-\frac{\sin \left[\frac{1}{2}(1-\alpha) \pi\right]}{\cosh [(1-\alpha) \ln (\omega \tau)]+\cos \left[\frac{(1-\alpha) \pi}{2}\right]}\right.
$$

Where $\eta_{0}$ : the lowest viscosity at very high temperature

$$
\begin{aligned}
& \eta_{\mathrm{s}} \text { : the highest viscosity; } \\
& \alpha \text { : phase shift. }
\end{aligned}
$$

So the COLE-COLE diagram, $\eta^{\prime}{ }^{\text {versus }} \eta^{\prime \prime}$, has the following equation:

$$
\eta^{\prime \prime}\left(\eta^{\prime}\right)=-\frac{\eta_{0}-\eta_{s}}{2 \tan \left[\frac{(1-\alpha) \pi}{2}\right]}+\frac{\left(\eta_{0}-\eta_{s}\right)^{2}}{4 \tan ^{2}\left[\frac{(1-\alpha) \pi}{2}\right]}+\sqrt{\left(\left(\eta^{\prime}-\eta_{s}\right)\left(\eta_{0}-\eta^{\prime}\right)\right)}
$$


(a)

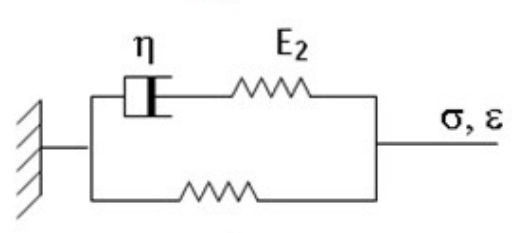

$\mathrm{E}_{1}$ (b)

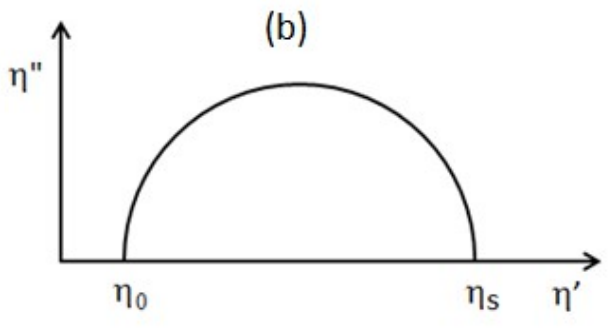

Figure 6. Zener model: schema (a), COLE-COLE Diagram (b)

The maximum of COLE-COLE diagram corresponds to $\omega_{\mathrm{m}}$. From this diagram the value of angular frequency, $\omega_{\mathrm{m}}$ related to the maximum point has been determined and then the relaxation time has been calculated at different temperatures, using the following equation (8):

$$
\tau=\frac{2 \pi}{\omega_{m}}
$$

The results have been shown in table 2 .

Table 2.Temperature dependence of relaxation time of PVDF, PP and PMMA.

\begin{tabular}{|c|l|c|c|c|c|c|}
\hline PVDF & Temperature $\left({ }^{\circ} \mathrm{C}\right)$ & 200 & 210 & 220 & 230 & 240 \\
\cline { 2 - 7 } & Relaxation time (s) & 0.42 & 0.33 & 0.27 & 0.23 & 0.19 \\
\hline PP & Temperature $\left({ }^{\circ} \mathrm{C}\right)$ & 170 & 180 & 190 & 200 & 210 \\
\cline { 2 - 7 } & Relaxation time (s) & 3.14 & 2.4 & 1.25 & 0.9 & 0.6 \\
\hline PMMA & Temperature $\left({ }^{\circ} \mathrm{C}\right)$ & 180 & 190 & 200 & 210 & 220 \\
\cline { 2 - 7 } & Relaxation time (s) & 13.7 & 7.5 & 4.3 & 2.5 & 1.7 \\
\hline
\end{tabular}

It was shown that the temperature dependence of relaxation time of PVDF, PP and PMMA can be presented by Arrhenius law (Figure 7) with the activation energy respectively of 25, 46 and $61 \mathrm{KJ} / \mathrm{mol}$. 


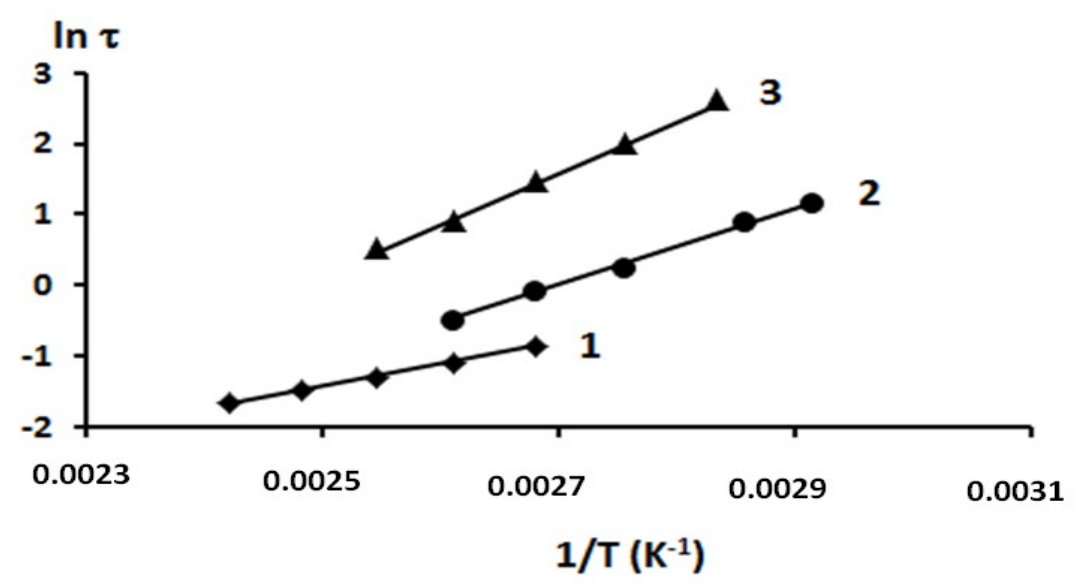

Figure 7.Temperature dependence of relaxation time, PVDF (1), PP (2) and PMMA (3)

\section{- Influence of temperature on surface tension}

The temperature dependence of surface tension of polymers is not very studied. There are only a few works in this field which indicate that the surface tension of polymer decreases by increasing of temperature [19-20]. A linear model has been proposed to show the relationship between surface tension and temperature [21].

\subsubsection{Effect of particle size}

The effect of the size of the particles on their coalescence rate may be explained by the inverse relationship between the size and the surface tension. As coalescence rate of two particles depends on the surface tension coefficient, so it decreases by increasing of the particle size. Figure 8 illustrates this effect for PP and PMMA.

The effect of particle size on coalescence rate may be explained also by the influence of thermal conductivity of the particles. In fact because of very low conductivity of the polymer, during coalescence, there is a temperature gradient between surface and centre of each grain. This temperature gradient may have influence on the viscosity so on the coalescence rate. However as the particles are very small, it seems that the effect of polymer conductivity (temperature gradient) is not very important and it can be neglected. 

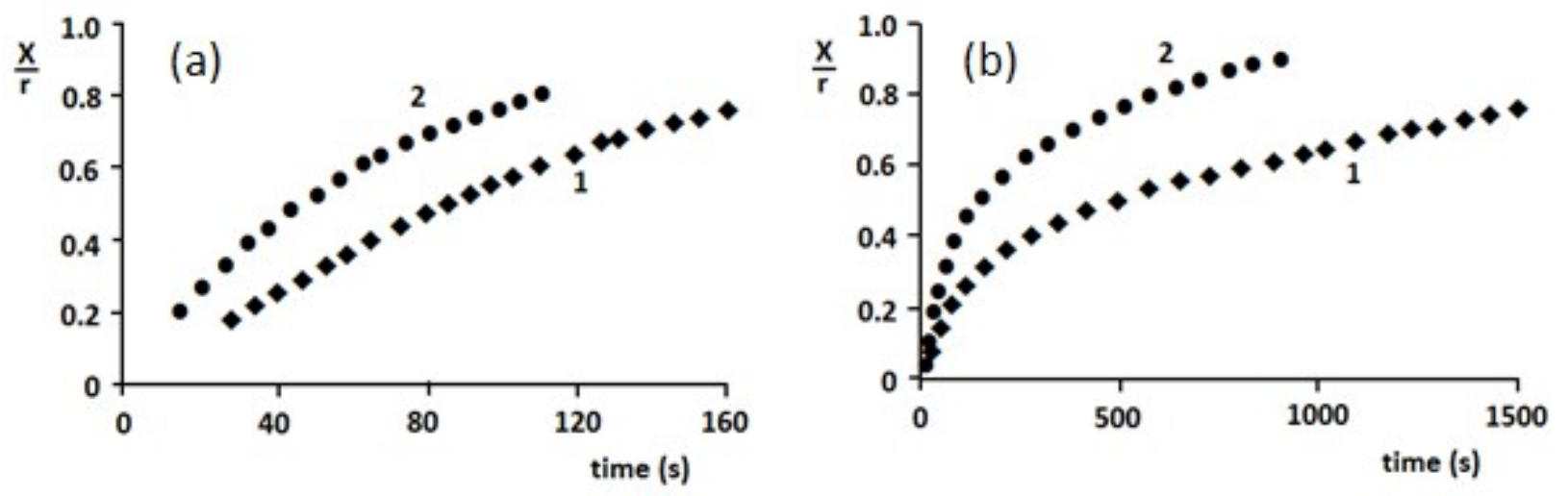

(c)

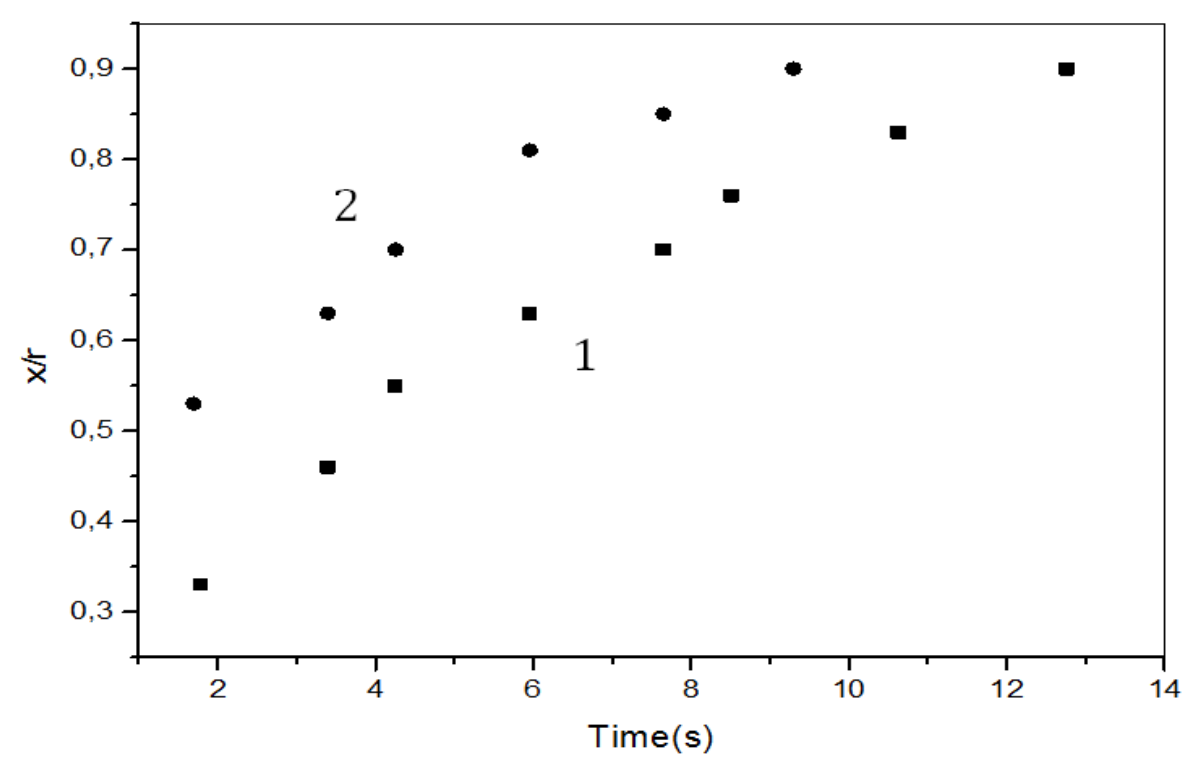

Figure 8.Influence of particle size on coalescence rate of:

a) PP particles at $190^{\circ} \mathrm{C} .700 \mu \mathrm{m}(1), 400 \mu \mathrm{m}(2)$

b) PMMA particles at $190^{\circ} \mathrm{C} .390 \mu \mathrm{m}(1), 280 \mu \mathrm{m}(2)$

c) PVDF particles at $190^{\circ} \mathrm{C} .100 \mu \mathrm{m}(1), 50 \mu \mathrm{m}(2)$

\subsubsection{Effect of third particle in contact with two grains during coalescence}

In order to study the effect of neighboring grains, the tests of coalescence of two grains in contact with a third one were carried out. The results were compared with that of two grains having the same size and heated under the same experimental conditions (Figure 9). It can be seen that the coalescence rate decreased because of this contact. 

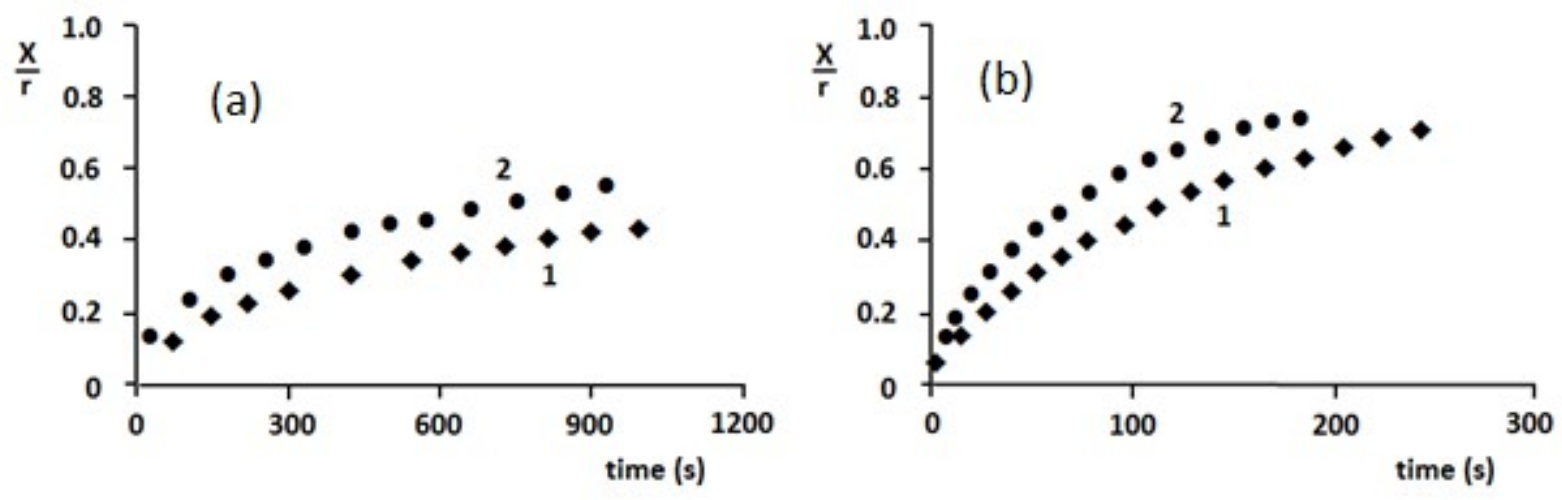

Figure 9.Effect of the third particle on coalescence rate of:

a) PP, two grains in contact only two grains (1), with third one (2).

b) PMMA, two grains in contact only two grains (1), with third one (2).

The rate of coalescence depends also on the position of third particle. Figure 10 shows the results of coalescence of two grains of PMMA and PP in contact with a third particle in different positions.
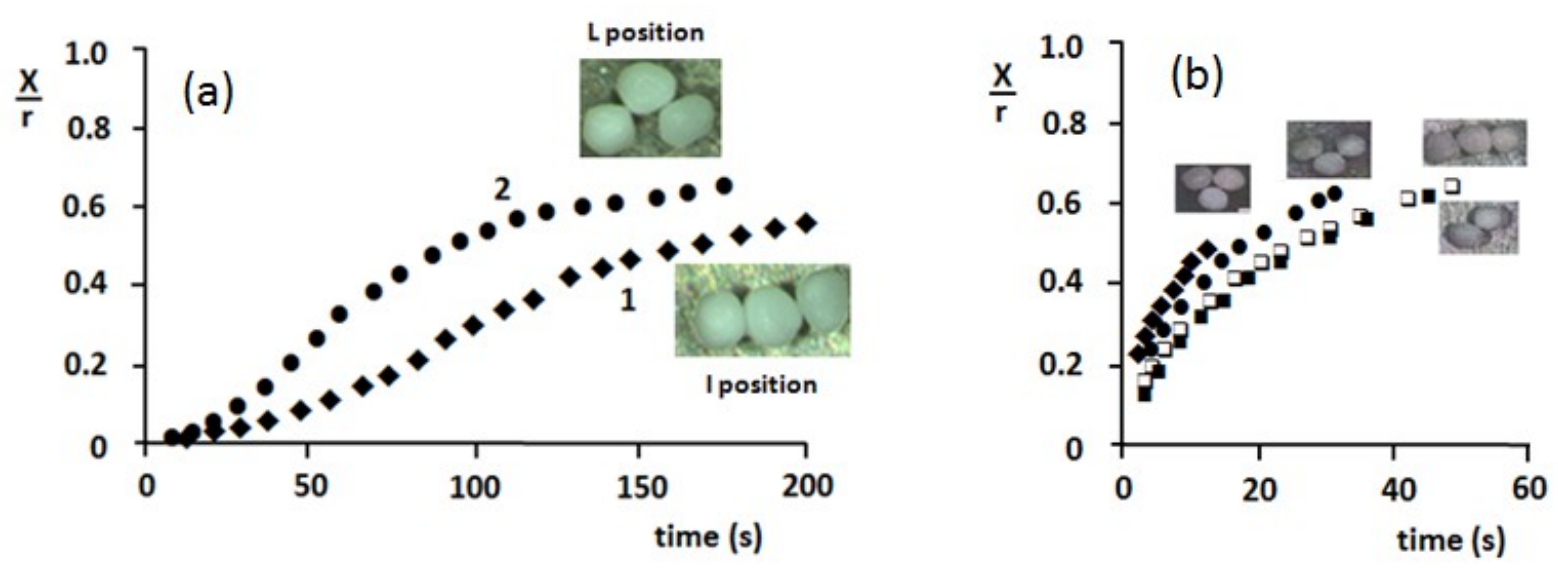

Figure 10. Coalescence curve for different positions of third grain of PMMA particle size

$$
280 \mu \mathrm{m}(\mathrm{a}) \text { and PP } 500 \mu \mathrm{m}(\mathrm{b}) \text { at } 190^{\circ} \mathrm{C} \text {. }
$$

These results show that the coalescence rate increases by reducing of the distance between the grains. For example, the coalescence rate of $\mathrm{L}$ position is more important than that of I position.

\subsubsection{Modelling}

\section{-Farz Factor (FF)}

The Bellehumeur's model has been used first to study the coalescence of two grains of PVDF, PP and PMMA. It was shown that for PVDF (small grains, less that $50 \mu \mathrm{m}$ of diameter), the 
experimental results confirm well those predicted by the model [22]. However, for PP and PMMA $(>500 \mu \mathrm{m}$ of diameter), there was a significant difference between experiment and theory.

At the beginning, this discrepancy had been related to the insulating property of these polymers. For PVFD, the effect of this factor is negligible because the grains are very small. But for PP and PMMA, as the diameter of the grains are relatively high, this effect cannot be neglected. In this case, this factor will create a temperature gradient in the grains and because of this temperature gradient; the assumption of isothermal coalescence is not very exact. In order to avoid this effect, the same coalescence test has been performed on preheated grains and the results were compared with the curve obtained by Bellehumeur's model. The result showed that the deviation between experimental and theoretical curves was decreased but remained always important [22].

As it was shown before, another parameter that may have influence on the coalescence of two grains is the effect of neighbouring grains. In fact the work done by surface tension during coalescence of two grains is not the same when these grains are in contact with other grains. So Bellehumeur's model, defined only for two grains cannot explain well the coalescence mechanism. It is then necessary to modify the model by a correction parameter, called Farz Factor (FF). This parameter will modify the surface tension coefficient in Bellehumeur's equation (9).

$$
\gamma^{\prime}=F F \cdot \gamma
$$

Where is the surface tension of only two grains and $\gamma^{\prime}$ the surface tension of two grains when one of them is in contact with a third grain. FF in this case presents always a value higher than one.

Figure 11 may be used to determine the mathematical expression of Farz Factor (FF). In this figure, $\mathrm{D}$ is the distance between the centre of grain $\mathrm{C}$ and the centre of interface between grains A and B. D may be defined by equation (10).

$$
D=\sqrt{\left(r_{0}+r\right)^{2}+\left(r^{2}-x^{2}\right)-2\left(r_{0}+r\right) \sqrt{\left(r^{2}-x^{2}\right)} \cos \beta}
$$


Where $\mathrm{r}$ is the radius of grains $\mathrm{A}$ and $\mathrm{B}, \mathrm{r}_{0}$ is the radius of grain $\mathrm{C}, \mathrm{x}$ is half of the neck (interface between grains $A$ and $B$ ) and $\beta$ the angle between segments $\mathrm{O}_{1} \mathrm{O}_{3}$ an $\mathrm{O}_{1} \mathrm{O}_{2}$.it varies between $60^{\circ}$ and $300^{\circ}$ when particle $\mathrm{C}$ remains always in contact with particle $\mathrm{A}$.

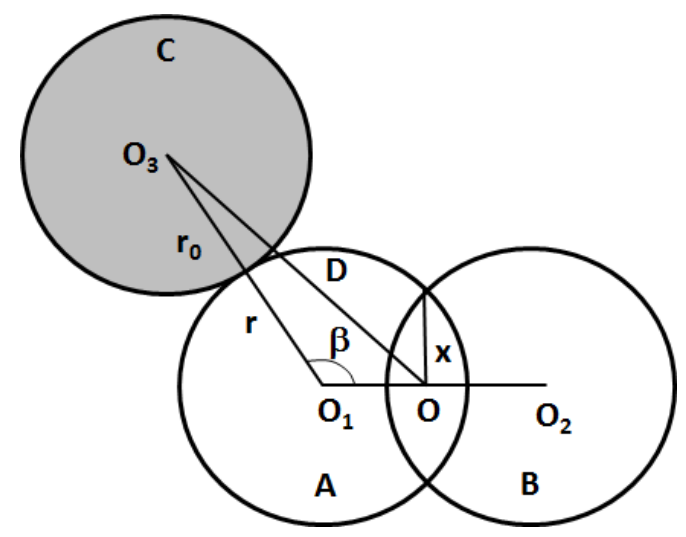

Figure 11.The effect of grain $\mathrm{C}$ during the coalescence of two grains $\mathrm{A}$ and $\mathrm{B}$.

The effect of grain $\mathrm{C}$ on coalescence between grains $\mathrm{A}$ and $\mathrm{B}$ depends on the value of $\mathrm{D}$ and in consequence on the value of $\beta, \mathrm{r}$ and $\mathrm{x}$. So FF depends also on the value of D. One may define this factor by a hypothetic relationship (equation (11))

$$
F F=1+\frac{1}{3}\left(\frac{r+r_{0}}{D}\right)
$$

- As it can be seen, the value of FF is always higher than one. It is not a constant value and depens on the values of $\beta, \mathrm{x}$ and $\mathrm{r}$. By variation of $\mathrm{x}$, this parameter changes during the coalescence of grains A and B

\section{-Position of the third particle}

In order to study the effect of the position of the third particle on the surface tension coefficient, the value of the FF and related tension surface coefficient have been cacultated at the beginning of coalescence $(\mathrm{x}=0)$ for different positions of particle $\mathrm{C}$ related to the particles $\mathrm{A}$ and $\mathrm{B}$, Figure 12. In this case, it has been considered that all three particles have the same diameter $(2 \mathrm{r}=200 \mu \mathrm{m})$. The results are shown in table 3 . 


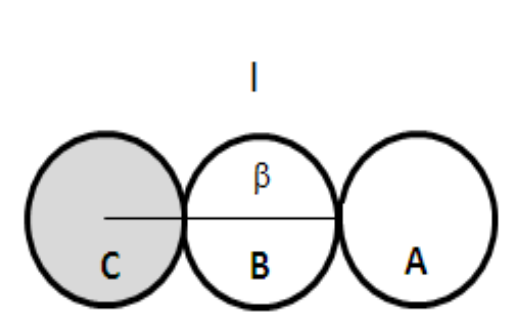

$\beta=180^{\circ}$

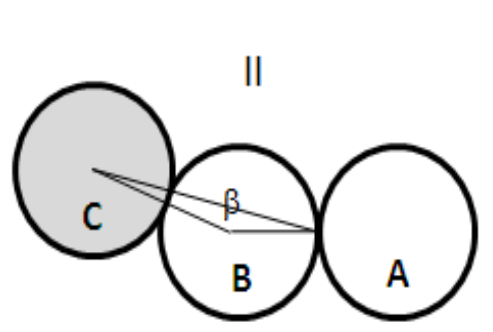

$\beta=150^{\circ}$

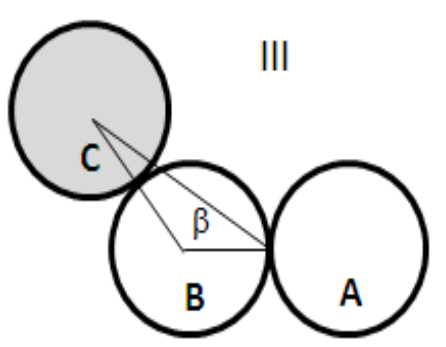

$\beta=120^{\circ}$

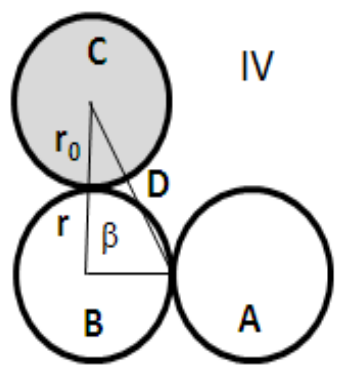

$\beta=90^{\circ}$

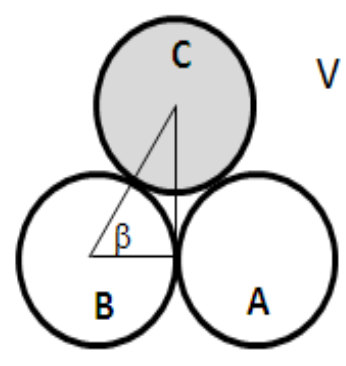

$\beta=60^{\circ}$

Figure 12.Different position of particle $\mathrm{C}$ during the coalescence of grains $\mathrm{A}$ and $\mathrm{B}$.

Table 3.Values of FF and modified surface tension coefficient for different position of particle $\mathrm{C}$ according the figure $12, \mathrm{r}=100 \mu \mathrm{m}$.

\begin{tabular}{|c|c|c|c|c|c|}
\hline Position & $\mathrm{r}(\mu \mathrm{m})$ & $\beta$ & $\mathrm{D}(\mu \mathrm{m})$ & $\mathrm{FF}$ & $\gamma^{\prime}(\mathrm{mN} / \mathrm{m})$ \\
\hline I & 100 & $180^{\circ}$ & 300 & 1.22 & 50.0 \\
\hline II & 100 & $150^{\circ}$ & 291 & 1.23 & 50.4 \\
\hline III & 100 & $120^{\circ}$ & 265 & 1.25 & 51.3 \\
\hline IV & 100 & $90^{\circ}$ & 224 & 1.30 & 53.3 \\
\hline V & 100 & $60^{\circ}$ & 173 & 1.38 & 56.7 \\
\hline
\end{tabular}

The value of FF is not constant and it is a function of $\mathrm{x}$ (interface between particles $\mathrm{A}$ and $\mathrm{B}$ ).

The variation of $\mathrm{FF}$ versus $\mathrm{x}$ for different positions of particle $\mathrm{C}$, according to the equations (10) and (11) is shown in figure 13. 


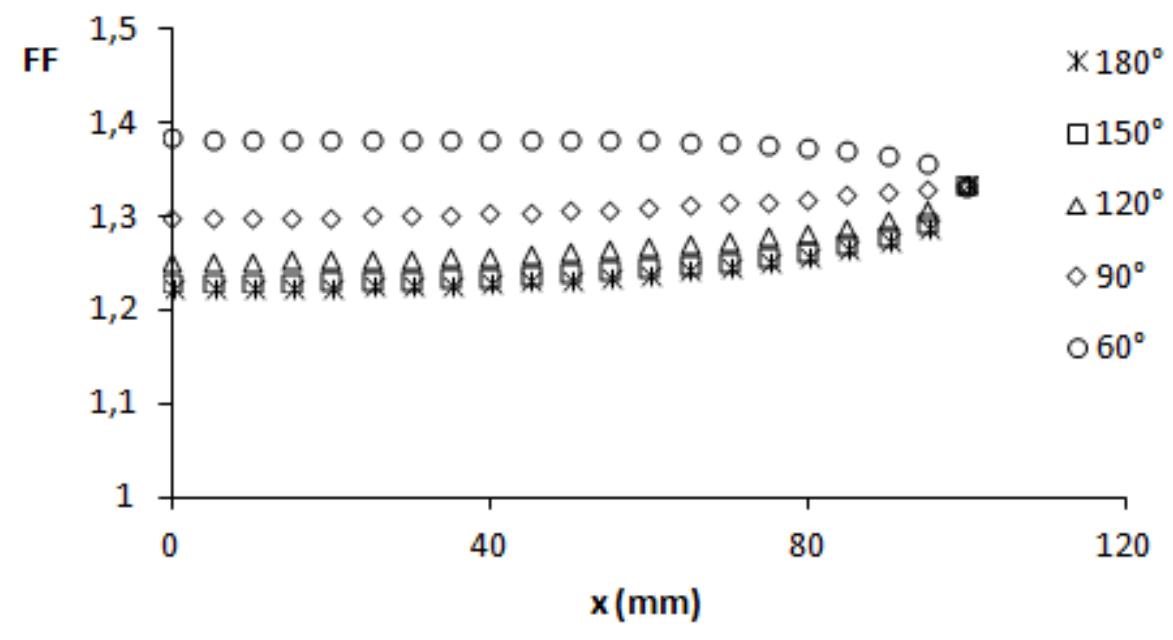

Figure 13.Variation of FF versus $\mathrm{x}$ for different positions according to the figure 12 .

At the beginning of the coalescence $(\mathrm{x}=0)$, the value of FF depends on the position of particle C. It is 1.22 for position $I$, when $\beta=180^{\circ}$ and 1.38 for position $V$, when $\beta=60^{\circ}$. This value does not remain the same during coalescence of particles $\mathrm{A}$ and $\mathrm{B}$, but the sense of variation is not the same for different position of particle $\mathrm{C}$. When $\mathrm{C}$ is in position $\mathrm{I}$, the value of $\mathrm{FF}$ increases, but when it is in position $\mathrm{V}$, this value decreases. However, for all position, FF has the same value at the end of the coalescence $(\mathrm{FF}=1.33)$.

\section{-Effect of $r$}

The initial and final value of FF does not depend on the position of particle C. However its variation versus $\mathrm{x}$ depends on the diameter of the particles. Figure 14 shows the variation of FF for the particles 


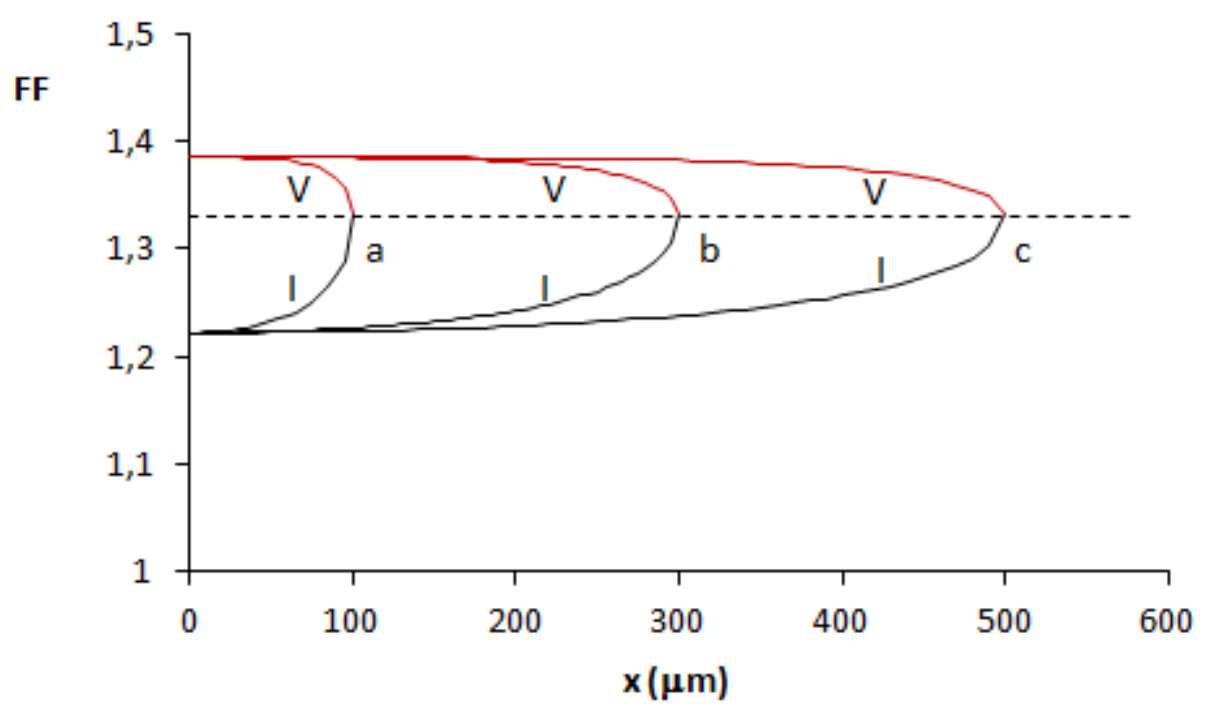

Figure 14 .Variation of FF versus $x$ for different values of $r: 100 \mu \mathrm{m}(\mathrm{a}), 300 \mu \mathrm{m}$ (b) and $500 \mu \mathrm{m}(\mathrm{c})$. This variation has been plotted for two positions of particle C: I and V.

In the case of the coalescence of grains of PMMA and PP, the rectified model by FarzFactor (FF) has been compared with experimental results for two different positions of neighboring particle. With this rectification, one can see a good correlation between the model and experimental results (Figure 15).
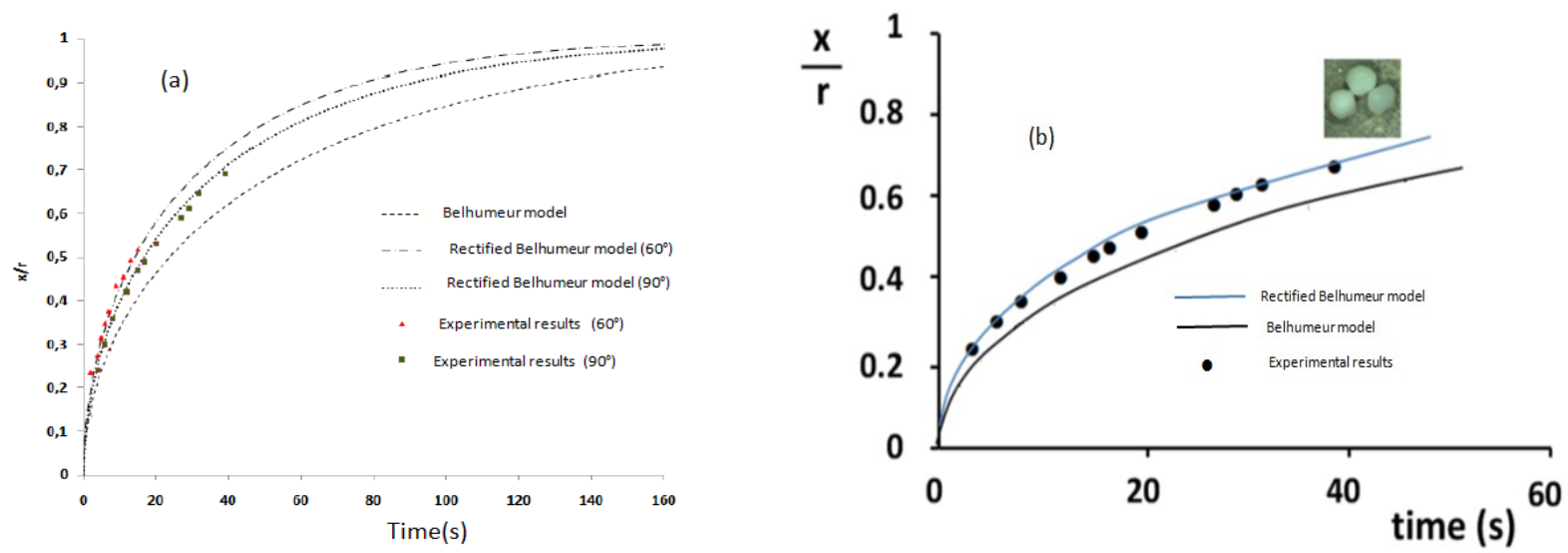

Figure 15.Modeling of the coalescence curves for two different grains configuration. (a) PP (b) PMMA. 


\subsection{Densification}

Densification means the increase of density under the effect of deleting the gas trapped between the grains. During rotational moulding, the densification [14-15, 17] phenomenon has a major effect on the properties of the final product.

In order to study this phenomenon during rotational moulding, the density of the powder of heated PVDF has been measured at different temperatures between $180^{\circ} \mathrm{C}$ and $220^{\circ} \mathrm{C}$. The results are presented on figure 17.

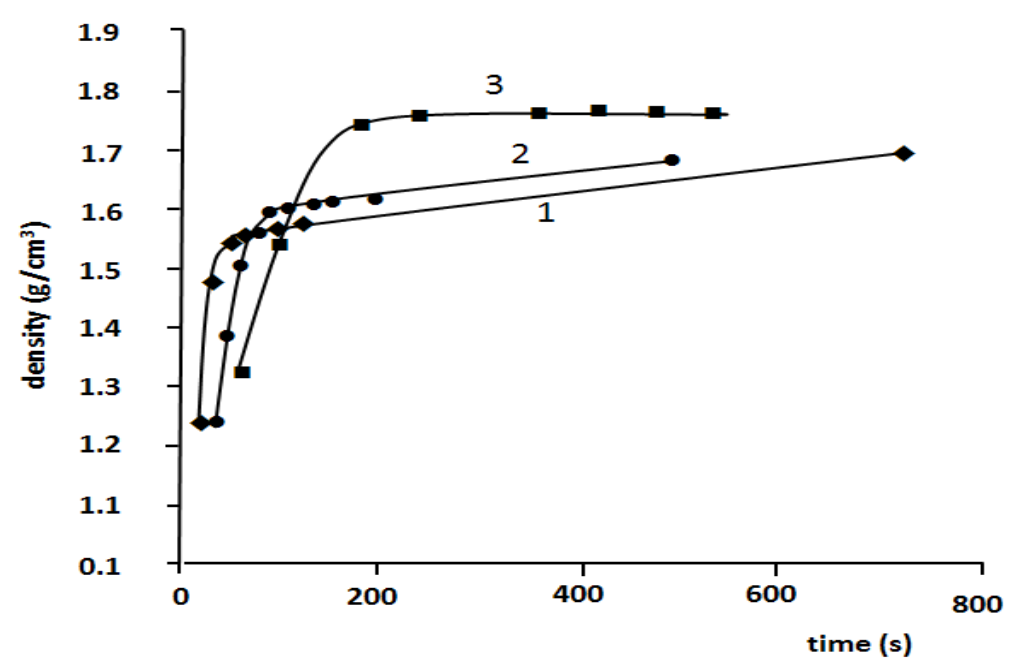

Figure 16.Evolution of density of PVDF during densification at $180^{\circ} \mathrm{C} \mathrm{(3),} 200^{\circ} \mathrm{C}(2)$ and $220^{\circ} \mathrm{C}(1)$

In the 3 cases, the density increases during the time. However one can distinguish two different stages

- The first stage corresponds to the fast increase in density. In this stage, the grains are not stuck yet. The air between the grains escapes rapidly through the free ways between the grains. This stage is directly controlled by the coalescence and its kinetic depends directly on the kinetic of this phenomenon.

- The second stage corresponds to the formation of the bubbles [23-24]. Indeed following coalescence, the grains are melted and welded. The interfaces between the grains are not free and air cannot escape any more by this ways. So air is trapped in molten polymer and the 
forms the bubbles. The migration of the air towards outside will be ensured by the diffusion of gas in molten polymer. If the heating is continued, the bubbles migrate towards outside at the end of 2nd stage of densification.

\subsection{Modelling}

As the mechanism is not the same, the modelling of densification must be performed for each stage separately. Concerning the second stage, the mechanism is based on diffusion of the gas of the bubbles into the molten polymer. This stage has been the subject of several works [21, 25]. In the scope of this paper the second stage has not been considered, only the first stage is described below.

For the first stage a model, based on Body Centre Tetragonal (BCT), is proposed(Figure 17), which connects the evolution of the densification to the interface between the grains during the coalescence. For coalescence, the Bellehumeur's model corrected with Farz Factor is used.
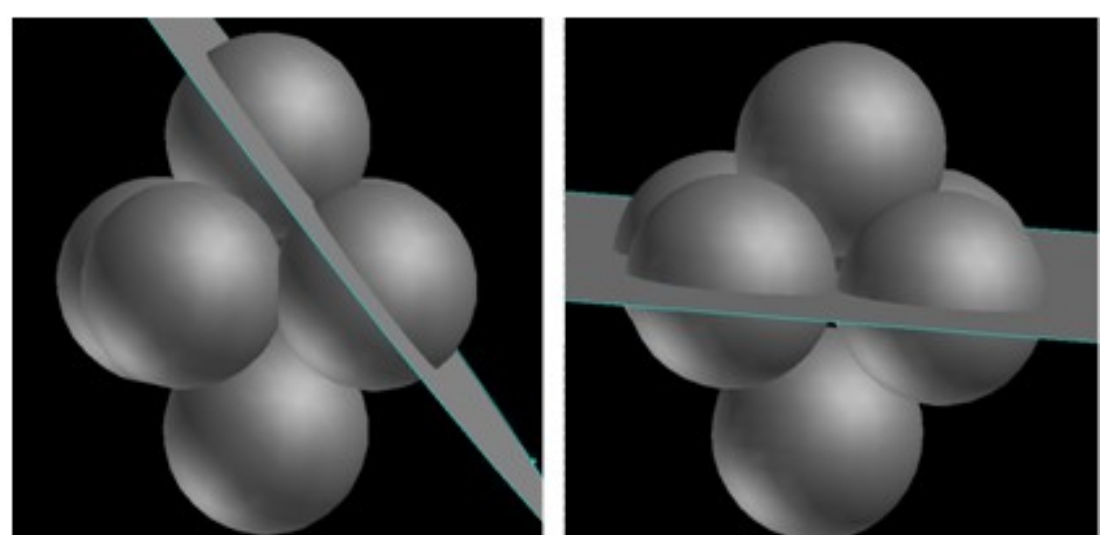

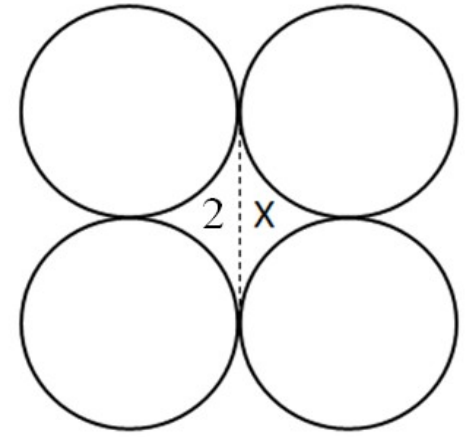

(a)

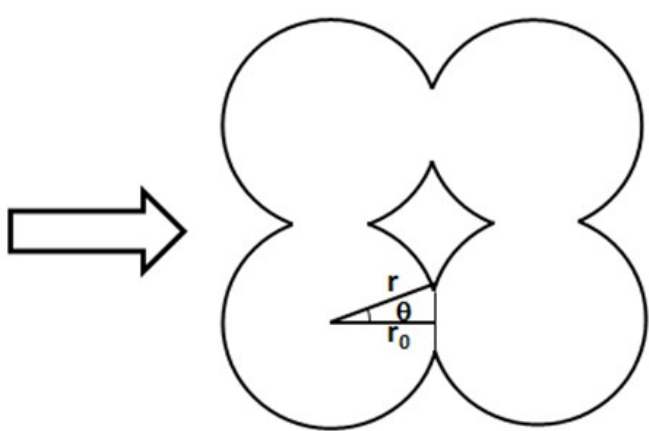

(b)

Figure 17.Body Centre Tetragonal (BCT) model in:3D (above) and 2D (below).

The model then can predict the evolution of density in function of the neck of coalescence. This model can be presented as follows:

$$
\left.d=\frac{m}{V}=\frac{m}{S^{3}-\left[2 S^{2}\left(r_{0}-\sqrt{r_{0}{ }^{2}-\left(\frac{S}{2}\right)^{2}}\right)\right.}\right](12)
$$


Where

$$
r_{0}=\sqrt{r^{2}+(r-X)^{2}} \quad S(t)=2 \sin \left(\frac{\pi}{4}-\theta\right) \quad \text { with } \quad \theta=\arcsin \left(\frac{r-X}{r}\right)
$$

Relative density is defined as following equation:

$$
d_{r}=\frac{d_{t}}{d_{\text {polymer }}}
$$

Where dt: the density of the polymer at $t$;

$\mathrm{d}_{\text {polymer: }}$ the density of the polymer at solid state;

This model then has been correlated with the experimental results (Figure 18).

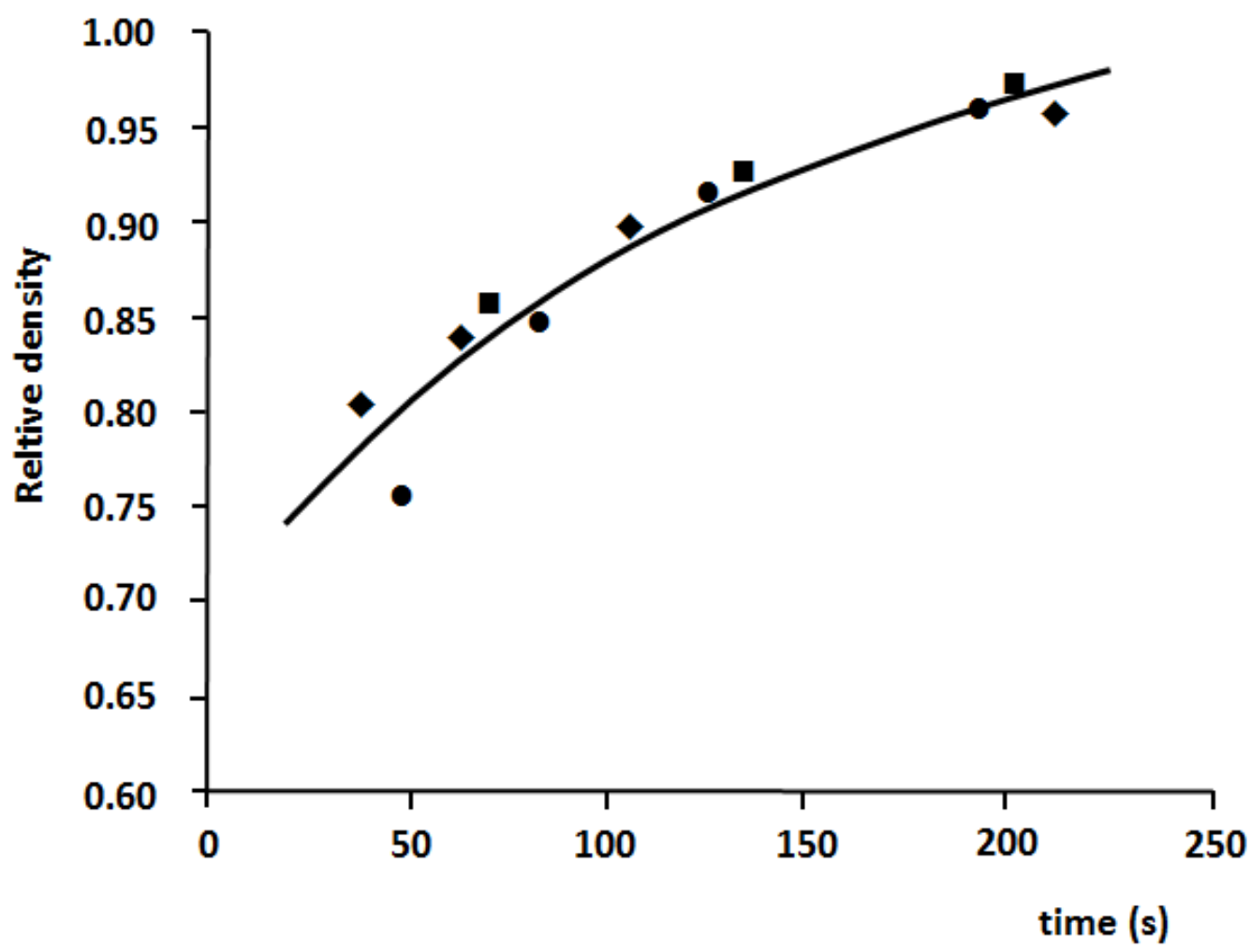

Figure 18. Modelling of the evolution of density during densification ( $\bullet$ test 1 -test $2 \bullet$ test 3 )

One can observe that the model reveals well the reality of the densification of this polymer. 


\section{Conclusion}

In conclusion, the coalescence of the two grains of thermoplastic polymer has been followed under optical microscope. The curve of evolution of interface between two grains has been plotted by a software image analyzer. Then the effect of different parameters, temperature, grain size on coalescence phenomenon has been studied. A new model has been proposed for modelling the coalescence of two grains considering the influence of other grains in contact. In this model the coefficient of tension surface has been rectified by a factor named FARZ factor. The results of modelling show a good correlation between model and experiments.

Concerning the densification, two different stages have been observed. In the first stage, the density increases rapidly. In this period, the migration of air is through the free way between the grains. In this stage the phenomenon depend directly on the coalescence of the grains. A Belhumeur's model modified using correction factor is used to predict the evolution of the density. It seems that the model explains well the density evolution in this period. The second stage corresponds to the bubbles formation in molten polymer. The migration of air, in this stage is controlled only by diffusion. 


\section{References}

[1]Crawford RJ and Throne JL(2002) Rotational molding technology, William Andrew Publishing, New York.

[2]TcharkhtchiA (2004)Rotomoulage de pièces en matière thermoplastique, Techniques de l'ingénieur, AM 3706, 1-15.

[3] Rao MA, Throne JL. Principles of rotational molding. Pol. Eng.Sc. 1972;12:237-64.

[4]Bonis LJ, Hausner HH, Lontz J. Sintering of Polymer Materials. Sintering and Plastic Deformation: Springer US; 1964. p. 25-47.

[5] Asgarpour M, Bakir F, Khelladi S, Khavandi A, Tcharkhtchi A. Characterization and modeling of sintering of polymer particles. Journal of Applied Polymer Science. 2011;119:2784-92.

[6] Greco A, Maffezzoli A. Polymer melting and polymer powder sintering by thermal analysis. Journal of Thermal Analysis and Calorimetry. 2003;72:1167-74.

[7] Bellehumeur CT, Bisaria MK, Vlachopoulos J. An experimental study and model assessment of polymer sintering. Polymer Engineering \& Science. 1996;36:2198-207.

[8] Rosenzweig N, Narkis M. Sintering rheology of amorphous polymers. Polymer Engineering \& Science. 1981;21:1167-70.

[9]Mazur S(1995)Coalescence of polymer particles in Polymer powder thechnology John Wiley\& Sonseds, Chiechester, England chapter 8.

[10] He Y, Howes T, Litster JD, Ko GH. Experimental study of drop-interface coalescence in the presence of polymer stabilisers. Colloids and Surfaces A: Physicochemical and Engineering Aspects. 2002;207:89-104.

[11]FrenkelJ(1945)Viscous flow of cristalline bodies under the action of surface tension. $\mathrm{J}$ Phys, 16:385-391.

[12]Lontz J F(1964)Sintering of polymer materials, in Fundamental phenomena in the material sciences,Plenum press, NEW YORK,pp 25-47.

[13] Pokluda O, Bellehumeur CT, Vlachopoulos J (1997) Modification of Frenkel's model for sintering. AIChE Journal 43 (12):3253-3256. doi:10.1002/aic.690431213.

[14]Pop-Iliev R, Rizvi GM, Park CB (2003) The importance of timely polymer sintering while processing polypropylene foams in rotational molding. Polymer Engineering \& Science 43 (1):40-54. 
[15]Bellehumeur Cl, Li L, Sun Q, Gu P (2004) Modeling of bond formation between polymer filaments in the fused deposition modeling process. Journal of Manufacturing Processes 6 (2):170-178

[16] Progelhof R C, Cellier G and Throne JL(1982)New technology in rotational molding powder densification, in "Society of Plastics Eng. Annual Technical Conference", San Francisco,USA, 28:627-629.

[17] Asgarpour M, Bakir F, Khelladi S, Khavandi A, Tcharkhtchi A (2012) 3D model for powder compact densification in rotational molding. Pol.Eng.Sc.52 (9):2033-2040.

[18] Park H, Thompson RB, Lanson N, Tzoganakis C, Park CB, Chen P (2007) Effect of Temperature and Pressure on Surface Tension of Polystyrene in Supercritical Carbon Dioxide. J.Phys.ChemB 111 (15):3859-3868. doi:10.1021/jp065851t

[19]Pérot E (2006) Optimisation et modélisation du procédé de rotomoulage. INSA de Lyon, [20]Muller J-D (2008) Etude des changements de phase de polymère dans le procédé de rotomoulage: coalescence et cristallisation couplées à la thermique du procédé. INSA de Lyon,

[21] Kontopoulou M, Vlachopoulos J (2001) Melting and densification of thermoplastic powders. Poly.Eng.Sci.41 (2):155-169. doi:10.1002/pen.10718

[22] Asgarpour M (2010) Analyse et modélisation de la coalescence et de la densification des grains de polymére lors du procédé de rotomoulage,Arts et Métiers ParisTech, [23] Gogos G (2004) Bubble removal in rotational molding. Poly.Eng.Sci 44 (2):388-394. doi:10.1002/pen.20035.

[24] Xu L, Crawford RJ (1993) Analysis of the formation and removal of gas bubbles in rotationally moulded thermoplastics. J.Mat.Sci.28 (8):2067-2074. doi:10.1007/bf00367563.

[25] A.G Spence. Analysis of bubble formation and removal in rotationally moulded products. $\mathrm{PhD}$ thesis, The Queen's University of Belfast, 1994. 